\title{
Extreme precipitation and climate change: the potential impacts on flooding
}

Conference or Workshop Item

Accepted Version

Champion, A., Hodges, K. and Bengtsson, L. (2010) Extreme precipitation and climate change: the potential impacts on flooding. In: BHS Third International Symposium, Managing the Consequences of a Changing Global Environment, 19-23 July 2010, Newcastle University. (Proceedings of the BHS Third International Symposium) Available at http://centaur.reading.ac.uk/28429/

It is advisable to refer to the publisher's version if you intend to cite from the work. See Guidance on citing.

Published version at: http://www.hydrology.org.uk/publications_list.htm

All outputs in CentAUR are protected by Intellectual Property Rights law, including copyright law. Copyright and IPR is retained by the creators or other copyright holders. Terms and conditions for use of this material are defined in the End User Agreement. 


\section{www.reading.ac.uk/centaur}

\section{CentAUR}

Central Archive at the University of Reading

Reading's research outputs online 


\title{
Extreme precipitation and climate change: the potential impacts on flooding
}

\author{
A. Champion ${ }^{* 1}$, K. Hodges ${ }^{1}$ and L. Bengtsson ${ }^{1}$ \\ ${ }^{1}$ National Centre for Earth Observation, University of Reading, Whiteknights, \\ Reading, RG6 6AL. \\ *Corresponding author: a.j.champion@reading.ac.uk
}

\section{Abstract}

Recent extreme precipitation events have caused widespread flooding to the UK. The prediction of the intensity of such events in a warmer climate is important for adaption strategies against future events. This study highlights the importance of using high-resolution models to predict these events. Using a high-resolution GCM it is shown that extreme precipitation events are predicted to become more frequent under the IPCC A1B warming scenario. It is also shown that current forecast models have difficulty in predicting the location, timing and intensity of small scale precipitation in areas with significant orography.

1. Introduction

Extreme precipitation events have the potential to cause both localised and widespread flooding. Recent flooding events in the UK have highlighted the risk these events pose to the UK and the challenges that are faced dealing with such events. There are also many challenges associated with forecasting the intensities and frequency of such events in future climates.

The summer of 2007 saw widespread flooding in the UK in both June and July. In June, the North-East was hit by severe flooding that caused losses of livestock and closure of main transport routes. In July, the southern region experienced 2 flooding events, the second of which caused some of the worst flooding seen in the UK in recent years. Each event was associated with a persistent extra-tropical system that caused extreme rainfall. The rainfall during these events spread over a large area, $100 \mathrm{~s}$ of $\mathrm{kms}$, and in some cases lasted for 18 hours.

Changes to the hydrological cycle are expected with a warming climate (Held and Soden, 2006). One of the consequences of a warming climate is an increase in the lower-tropospheric water vapour, which in turn affects the hydrological cycle. The global hydrological cycle is constrained by relatively small changes in radiative fluxes, which means that there is a reduced mass exchange between the boundary layer and the atmosphere. Given most of this exchange occurs in the Tropics, the convective mass flux must decrease.

This results in an increase in the poleward transport of water vapour, causing the evaporation minus precipitation pattern to increase proportionally to the lower- 
tropospheric water vapour. This implies that wet areas will get wetter and dry areas will get drier.

Observational studies (Osborn et al., 2000) have looked at daily raingauge totals for 1961 - 1995 and noted an increase in intense precipitation events during the winter period and a decline in intense precipitation events for the summer period. The increase in precipitation during winter was seen as more frequent wet days with more precipitation seen on these days. It was suggested that this was driven, in part, by an increased westerly zonal flow.

For the summer precipitation, there is an increase in the contribution from light precipitation days and a decrease in the number of the intense wet days, suggesting a decrease in the number of intense precipitation events for the summer; however this trend was less coherent than the increase in winter precipitation. They also noted however that the downward trend starts from anomalously high values in the 1960s, and that the trend appears to be a return to earlier levels rather than to anomalously low values.

A review by Wilby et al., 2008, suggests that trends seen in flood frequencies from river flows have a large uncertainty, and do not necessarily reflect an increase in flood risk in warmer climates. However results from Regional Climate Models suggest increases in extreme events and an increased risk of flooding in the UK. Other studies also suggest an increase in the heaviest precipitation events over the UK in both Global Climate Model simulations (Easterling et al., 2000, Murphy and Mitchell, 1995) and other Regional Climate Model simulations (Jones and Reid, 2001).

Bengtsson et al., 2009 discuss that in a warmer climate the cumulative precipitation along the tracks of extra-tropical cyclones is expected to increase, with extreme precipitation increasing close to the globally averaged increase in column water vapour. Given the summer 2007 UK floods were caused by the presence of a series of extra-tropical cyclones, the potential impact of an increase in extreme extratropical cyclones on the UK is large.

Section 2 compares the results from Bengtsson et al., 2009 with the results from a higher-resolution Global Climate Model (GCM), and discusses whether more extreme extra-tropical storms are predicted for the UK. Section 3 goes on to examine the summer 2007 flooding event, using a Limited Area Model (LAM) to investigate whether a $4 \mathrm{~km}$ LAM is able to predict the rainfall intensity observed during the $20^{\text {th }}$ July event. The output from the LAM is compared to raingauge data. Section 4 presents a discussion of the results and future work.

\section{Global Climate Model}

The Global Climate Model (GCM) used in this study is the Max-Planck Institutes' (MPI) ECHAM5 atmosphere model (Roeckner et al., 2003) integrated at a T319 spectral resolution $(40 \mathrm{~km})$ with 31 levels in the vertical using the 'time-slice' method. 
The climate is simulated for two 20 year periods that are representative of the end of the $20^{\text {th }}(1980-2000)$ and $21^{\text {st }}(2080-2100)$ centuries, using the IPCC warming scenario $\mathrm{A} 1 \mathrm{~B}$. These will be hereafter referred to as $20 \mathrm{C}$ and $21 \mathrm{C}$ respectively.

Extreme precipitation events are identified in the model by first identifying extratropical storms. Storms are identified in the model using the TRACK software developed by Hodges, 1995. In this study the storms were identified using the 850 $\mathrm{hPa}$ relative vorticity field at a reduced resolution of T42 $(300 \mathrm{~km})$ to enable reliable tracking of the storms (Hoskins and Hodges, 2002, for details). The full resolution properties are extracted from the data along the storm trajectories.

Post-tracking filters are applied to consider only those storms that lasted for more than 2 days and travelled further than $1000 \mathrm{~km}$. In this case only extra-tropical storms, or tropical storms that moved into the extra-tropics, were kept. The distance filter, to include stationary storms as experienced during the summer of 2007, was removed to determine whether these types of storms affected the results. It was found that the number of low intensity precipitation events $\left(<1.5 \mathrm{~mm} \mathrm{hr}^{-1}\right)$ increased by almost $50 \%$, however for events $>1.5 \mathrm{~mm} \mathrm{hr}^{-1}$, and in the tails (extremes), the inclusion of stationary storms made no difference to the results.

The full resolution referencing of the vorticity field to the tracks is obtained by searching for the maximum value within a 5 degree spherical arc radius of the storm's centre. The precipitation was computed as the area average within the same 5 degree area from the storm's centre. Other size search radii were tested, however 5 degrees was found to capture the full extent of the rainfall. Other fields were extracted however are not presented here. The frequencies of the tails of the distributions were scaled to 30 years to compare to an earlier paper by Bengtsson et al., 2009 which used a T213 integration run, which was run for two 30 year periods.

Figure 1 shows the maximum vorticity intensity along the storm track. The solid lines are the results from the higher-resolution T319 run, the dashed lines are the results from the T213 run. By comparing the solid to the dashed lines, the consequences of a higher resolution GCM can be seen. For all four seasons, the higher-resolution run has a broader distribution that is shifted towards the more intense storms, in comparison to the lower-resolution run. Both runs identified a similar number of storms, meaning the areas under the curves are the same. 

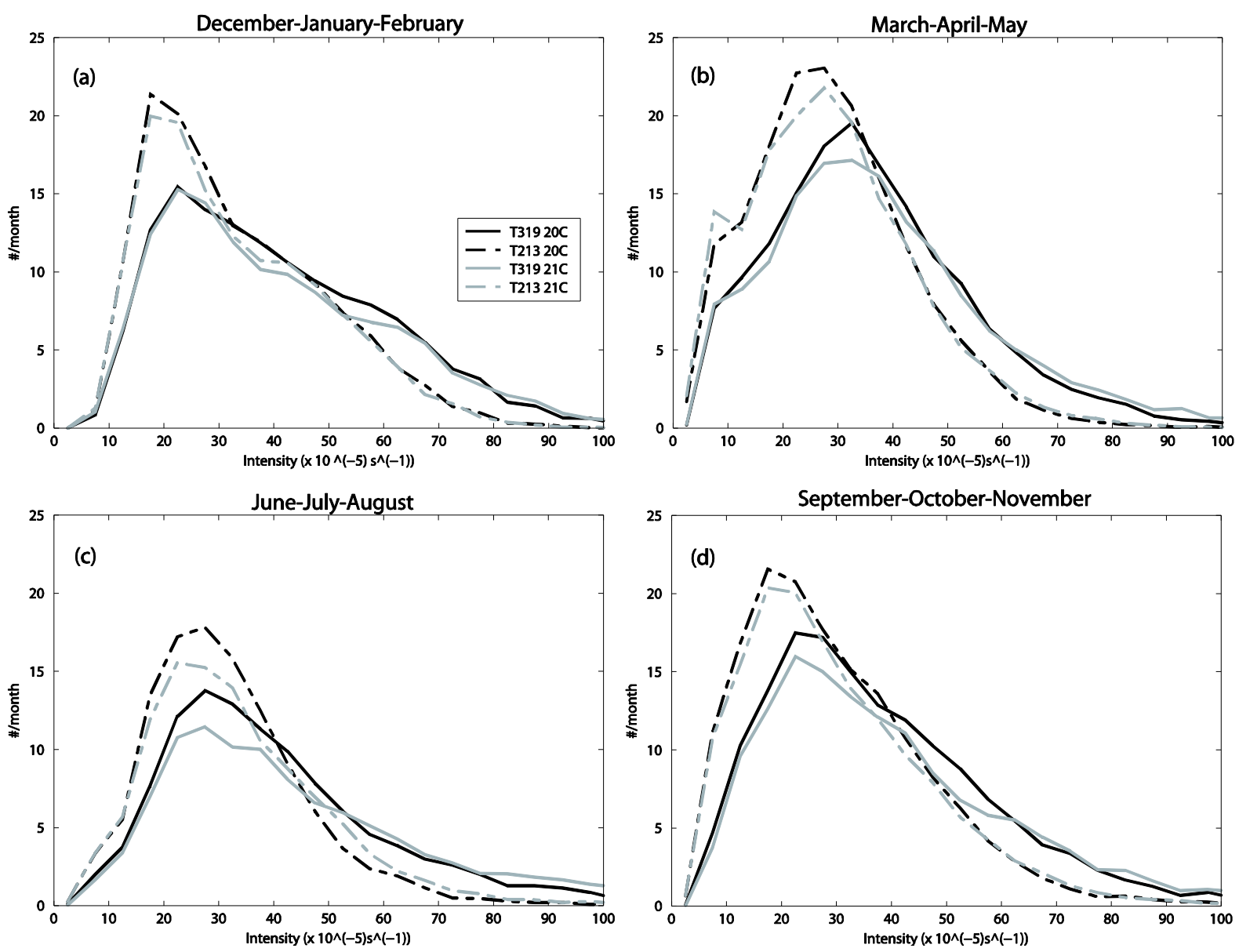

Figure 1: Maximum vorticity intensity along the storm track within a 5 degree area of the storm's centre for: a) December-January-February, b) March-April-May, c) JuneJuly-August and d) September-October-November. The T319 resolution is shown by the solid lines, dashed liens are the T213 resolution. The black lines represent the $20 C$, the grey lines the $21 C$.

The effect of a warming climate on the storms can be seen by comparing the black $(20 \mathrm{C})$ and grey (21C) lines. For vorticity there is little change in the distribution due to a warming climate. Figure 2 shows the area average precipitation along the storm track for a 5 degree area of the storm's centre for the Northern Hemisphere, with the insets showing the tails of the distributions scaled to 90 months. Similar to Figure 1, the effect of an increase in resolution can be seen by comparing the solid (highresolution) to the dashed (lower-resolution) lines, and the effect of a warming climate by comparing the black (20C) to the grey (21C) lines. 
Area Average Precipitation
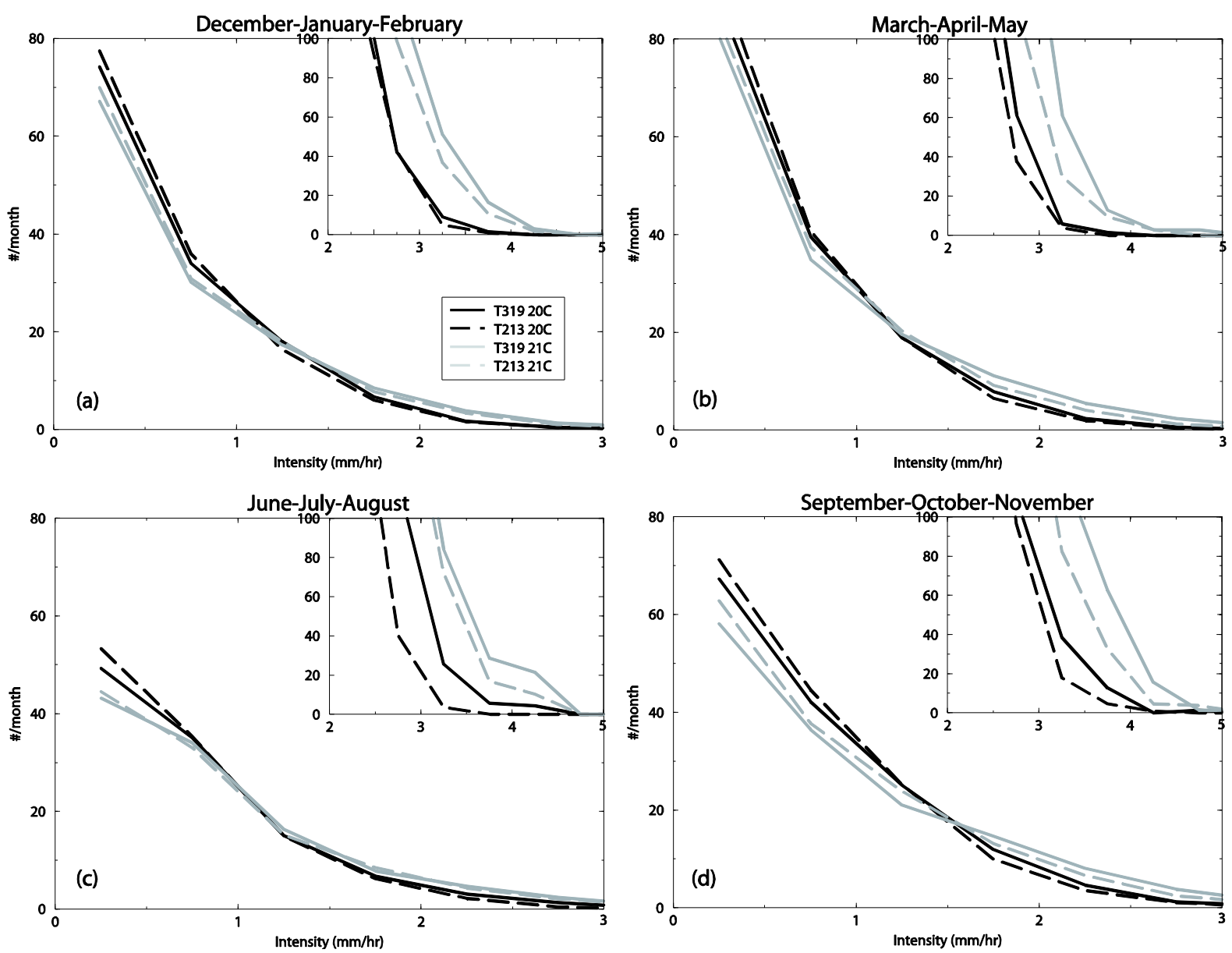

Figure 2: Area average precipitation along the storm track within a 5 degree area of the storm's centre for: a) December-January-February, b) March-April-May, c) JuneJuly-August and d) September-October-November. The T319 resolution is shown by the solid lines, dashed liens are the T213 resolution. The black lines represent the $20 \mathrm{C}$, the grey lines the 21C. The insets show the tails of the distributions scaled to 90 months.

The increase in resolution identifies fewer low intensity precipitation events, for all seasons and both climates. For events $>1.5 \mathrm{~mm} \mathrm{hr}^{-1}$, a greater number of events are identified in the higher-resolution run. This is particularly evident in the tails of the distributions, the extreme events $\left(>2.5 \mathrm{~mm} \mathrm{hr}^{-1}\right)$.

This increase in frequency results in the return rate of storms to decrease. A $3.5 \mathrm{~mm}$ $\mathrm{hr}^{-1}$ event in DJF will occur at least 3 times as frequently at the end of $21 \mathrm{C}$. This increase is larger in JJA which is affected by tropical storms, with a $3.5 \mathrm{~mm} \mathrm{hr}^{-1}$ event occurring almost 6 times as frequently at the end of the $21 \mathrm{C}$.

Whilst $3.5 \mathrm{~mm} \mathrm{hr}^{-1}$ in itself does not represent a flood risk, the resolution of the GCM means that extreme intensities that occur on a small scale $(<40 \mathrm{~km})$ cannot be resolved. To identify whether these events will cause small scale extreme intensity precipitation, they will be downscaled and used in a Limited Area Model. 


\section{Limited Area Model}

A Limited Area Model (LAM) was used to investigate whether current forecast models are able to capture the intensity and distribution of extreme precipitation events. The $20^{\text {th }}$ July 2007, one of the summer 2007 UK floods, was used as a case study as an example of extreme precipitation caused by an extra-tropical storm, with small scale high rainfall intensity embedded within the storm.

The LAM used in this study was the UK Met Office's Unified Model (UM), version 6.1, in a limited area format. The model is a non-hydrostatic model with convective processes parameterised within the model. The area chosen ran from $12 \mathrm{~W}$ to $10 \mathrm{E}$, and from $44 \mathrm{~N}$ to $62 \mathrm{~N}$. This covers the UK and parts of Western Europe, allowing the large scale nature of the event to be captured.

The model was run at two resolutions, $12 \mathrm{kms}$ and $4 \mathrm{kms}$. Both resolutions used the European Centre for Medium Range Weather Forecasts (ECMWF) operational analysis for initial conditions, with boundary conditions used every 6 hours, also from ECMWF operational analysis.

It was found that the model had a "spin-up" time for the precipitation. Initially the LAM was run for 15 days with the conditions re-initialised every 6 hours with the ECMWF operational analysis. The spin-up time for the model is at least 6 hours, with realistic rainfall only occurring after 12 hours. This meant that the rainfall had not "spun-up", resulting in rates that never exceeded $2 \mathrm{~mm} \mathrm{hr}^{-1}$. Therefore it was decided to run the models for 48 hours, with only the boundary conditions being supplied every 6 hours.

Figure 3 shows the total precipitation rate at $12 Z$ on the $20^{\text {th }}$ July from the $12 \mathrm{~km}$ run and the $4 \mathrm{~km}$ run started at the same time as the $12 \mathrm{~km}$ run (00Z on the $\left.19^{\text {th }}\right)$. The radar imagery from the Met Office's NIMROD nowcasting radar network is shown, which has a $1 \mathrm{~km}$ resolution. A quantitative assessment of the intensity of the rainfall is done later using raingauge data. 


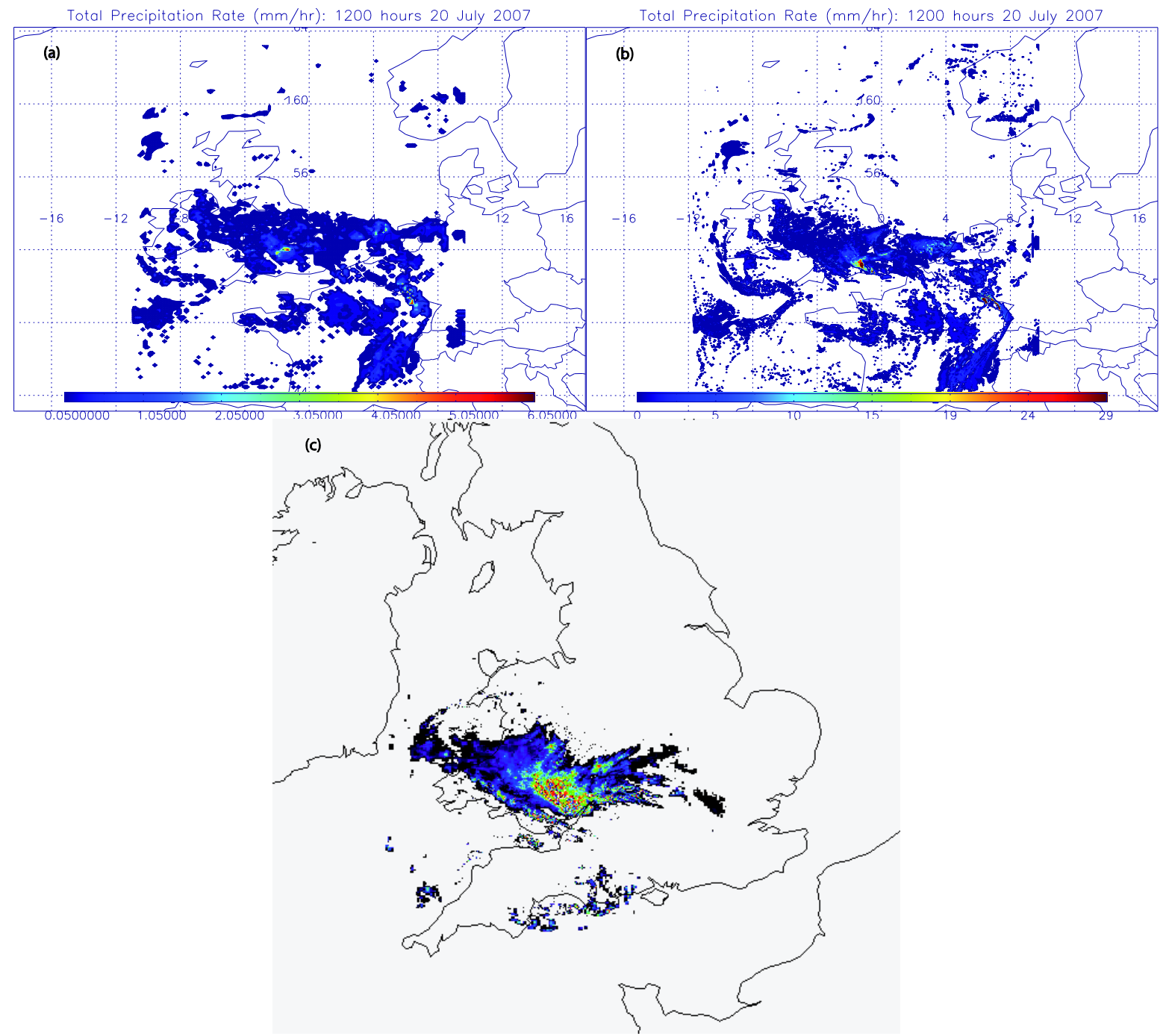

Figure 3: (a) $12 \mathrm{~km} 48$ hour forecast, (b) $4 \mathrm{~km} 48$ hour forecast and (c) $1 \mathrm{~km}$ resolution radar plot for $12 Z$ on the $20^{\text {th }}$ July.

It can be seen in Figure 3 that both the $12 \mathrm{~km}$ and $4 \mathrm{~km}$ run pick up the broad distribution of the rainfall. A qualitative assessment of the intensity shows that neither model gets the position of the extreme rainfall in the same location as in the radar data. The models also predict a larger areal extent to the rainfall than seen in the radar.

The $4 \mathrm{~km}$ run shows a lot more small scale activity in the storm, and forecasts much more intense rainfall than the $12 \mathrm{~km}$ run. Given the $20^{\text {th }}$ July event had a series of small scale activity, the detail identified in the $4 \mathrm{~km}$ run is important for looking at the potential flooding impact.

The precipitation rates from the model were verified using raingauge data. The raingauges were from the Environment Agency's (EA) raingauge network which were provided in a time-of-tip format. This records when the bucket of the raingauge tips, representing $0.2 \mathrm{~mm}$ of rain. This was converted into hourly rainfall rates in $\mathrm{mm} \mathrm{hr}^{-1}$. 
The raingauge network is not on a regular grid and several stations could not be used due to issues with the raingauges, ranging from the gauges themselves being under water, to some stations recording "anomalously high rainfall rates" and were discounted by the EA. However this still left 66 stations which covered the West Midlands and Thames regions.

A series of runs of the LAM were done, investigating different lead times and the consequences of the lead times on the peak precipitation intensity forecast. Table 1 lists the different runs.

Table 1: The LAM runs used in this study with different resolutions and lead times before the peak precipitation.

\begin{tabular}{|c|c|c|}
\hline Resolution $(\mathrm{kms})$ & Start Date and Time & $\begin{array}{c}\text { Lead Time to Peak } \\
\text { Precipitation (hours) }\end{array}$ \\
\hline 12 & $00 \mathrm{Z} 19^{\text {th }}$ July & 36 \\
\hline 4 & $00 \mathrm{Z} 19^{\text {th }}$ July & 36 \\
\hline 4 & $12 \mathrm{Z} 18^{\text {th }}$ July & 48 \\
\hline 4 & $12 \mathrm{Z} 19^{\text {th }}$ July & 24 \\
\hline 4 & $00 \mathrm{Z} 20^{\text {th }}$ July & 12 \\
\hline
\end{tabular}

An initial validation study was to select all the raingauges within a domain labelled as the "West Midlands Domain", and take the average hourly intensity for all the raingauges. The domain extends from $7.05 \mathrm{~W}$ to $0.4 \mathrm{~W}$ and $51.1 \mathrm{~N}$ to $52.9 \mathrm{~N}$, as shown in Figure 4. The same domain was selected within the LAM, and the average of the domain was also taken. This was done for each of the $4 \mathrm{~km}$ runs as well as the 12 $\mathrm{km}$ run. Figure 5 shows the results from this study. 


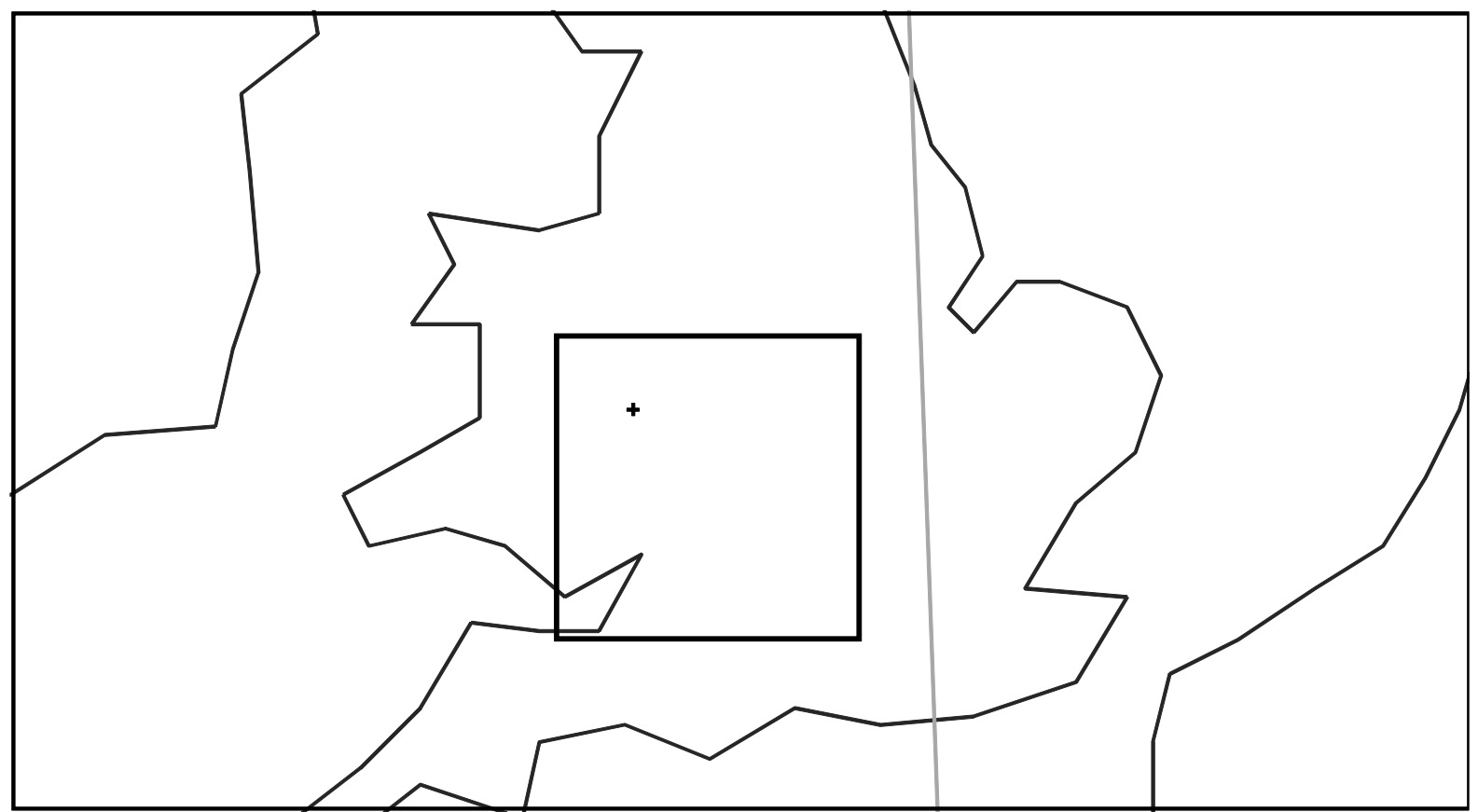

Latitude of pole 37.5; Longitude of pole 177.5; Grid length .036 x .036; Dimensions 45 x 45; Latitude of BLC -1.2; Longitude of BLC -0.4

Figure 4: Location of the "West Midlands Domain" for the raingauge to LAM output comparison.

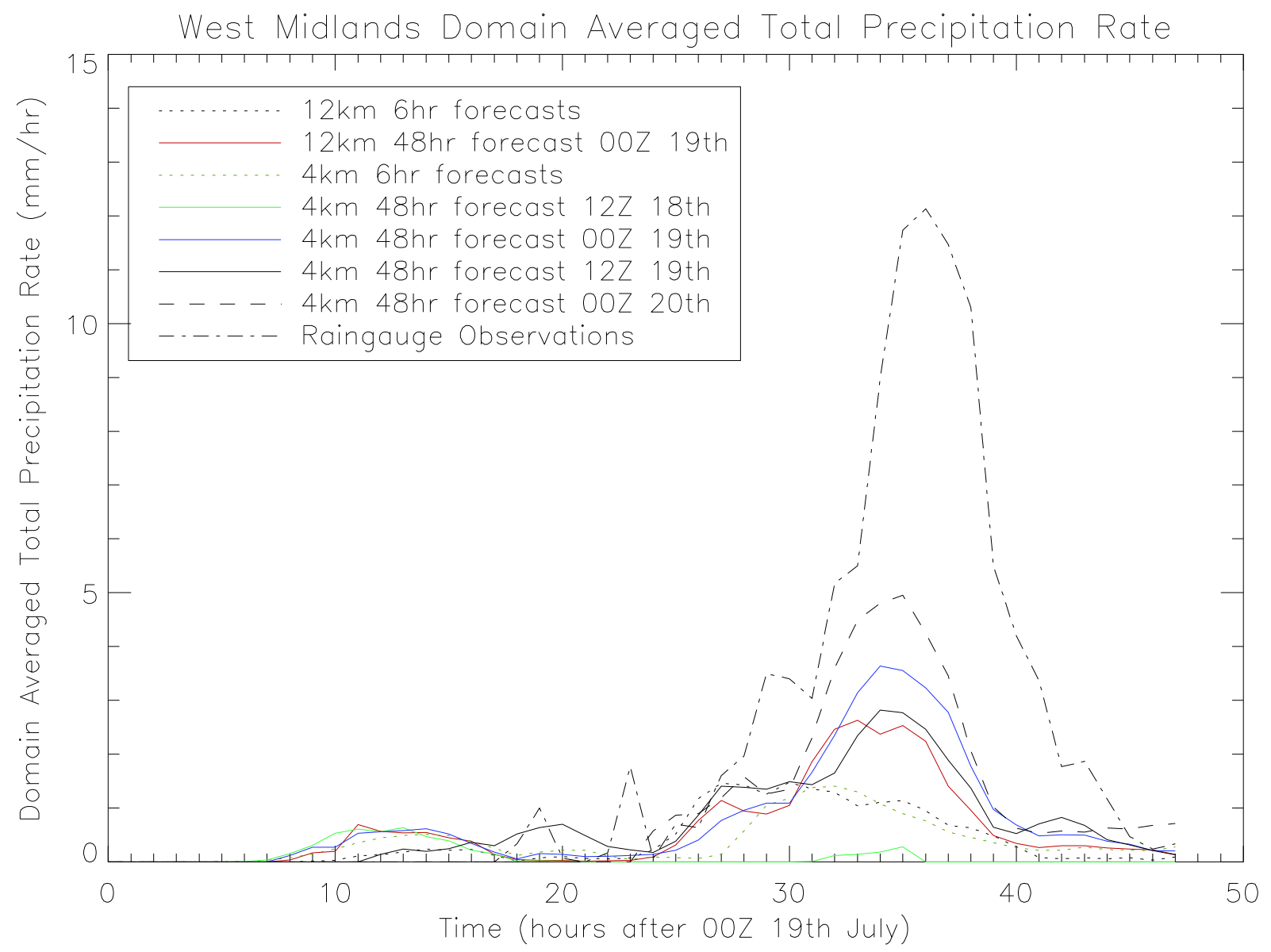

Figure 5: Comparison between raingauge observations (dot-dashed) and LAM runs. 
One of the first features that can be clearly seen is that the rates forecast in the model are significantly smaller than the rates observed by the raingauges. Whilst such a large difference is an important result, it should not be expected for the model to predict the same rates as the raingauges due to the averaging of the area. This is due to sampling problems due to fewer raingauges than model grid points, and the raingauges are not on a regular grid.

This effect can be made smaller by reducing the size of the domain, however as the domain becomes smaller, fewer raingauges are included in the validation, and it also increases the risk of missing the peak rainfall in the model. Several domain sizes were tested, and the "West Midlands" domain presented in Figure 5 was determined as the most useful.

A more important result from Figure 5 is the effect of the lead times on the peak rate forecast, the effect of resolution, and the accuracy of the timing of the rainfall by the model. Presented in Figure 5 are also the two runs which were re-initialised with ECMWF operational analysis data every 6 hours, at both a $12 \mathrm{~km}$ and a $4 \mathrm{~km}$ resolution, represented by the two short dotted lines.

The solid red and black lines represent two 48 hour forecasts run at $12 \mathrm{~km}$ and $4 \mathrm{~km}$ respectively, started at $00 Z$ on the $19^{\text {th }}$ July, 36 hours before the peak rainfall. Both forecasts are similar in intensities, however the $4 \mathrm{~km}$ run has a sharper peak rainfall distribution with the timing of the peak in-line with the observations. The $12 \mathrm{~km}$ run has a broader peak and predicts the peak rainfall earlier that the observations. The 4 $\mathrm{km}$ run also picks up a later rainfall event, 42 hours into the forecast that is represented in the observations but not in the $12 \mathrm{~km}$ run. This rainfall event is lower in intensity, which may be the reason the coarser $12 \mathrm{~km}$ resolution doesn't pick it up.

The solid green, blue and black lines, and the long dashed black line, represent the 4 $\mathrm{km}$ runs started 48 hours ( $12 Z$ on the $18^{\text {th }}$ ), 36 hours ( $00 Z$ on the $19^{\text {th }}$ ), 24 hours ( $12 Z$ on the $19^{\text {th }}$ ) and 12 hours ( $00 Z$ on the $20^{\text {th }}$ ) before the peak rainfall respectively. It is quite clear from the green line that 48 hours into the forecast the model no longer accurately represents the rainfall in respect to the observations.

As the lead time to the peak rainfall is decreased the intensity of the peak rainfall rate increases, with the 12 hour lead time predicting the largest peak rainfall rate of all the forecasts. The distributions of the peak rainfall rate for all lead times of 36 hours or less are similar, with the peak rainfall occurring within an hour of the observed peak rainfall, and with a relatively sharp peak in contrast to the 6 hourly forecasts.

A more direct comparison can be made between the model and the observations. Instead of averaging over a domain, the location of a particular raingauge can be searched within a model run and the intensities compared. Initially this was done with the 12 hour lead time forecast (starting at $00 Z$ on the $20^{\text {th }}$ ) as this had already shown the closest agreement to the observations. Figure 6 shows two example raingauge locations, one showing good agreement with the model (Figure 6a) and another showing poor agreement with the model (Figure 6b). 

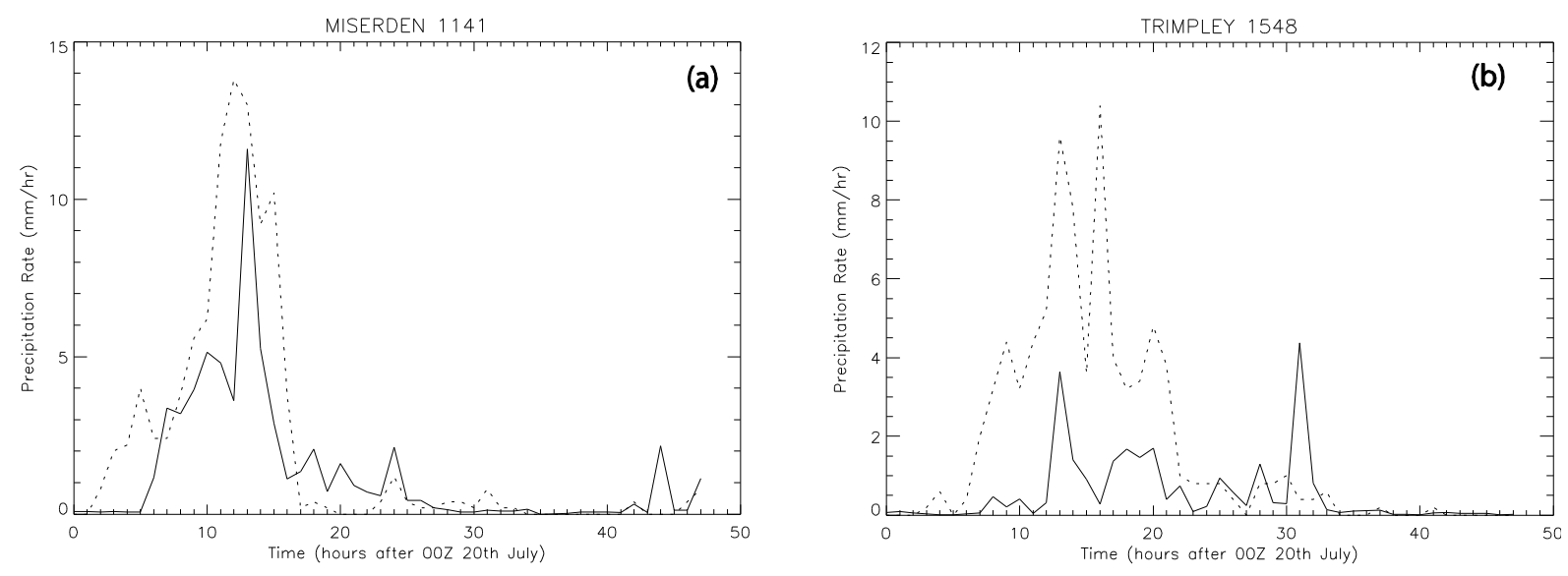

Figure 6: Two examples comparing specific raingauges to a 0.1 degree squared area around the raingauge's location within the LAM, (a) good agreement, (b) poor agreement. The dot-dashed lines represent the raingauges, the solid lines represent the LAM output.

Preliminary results highlight the variability of precipitation, on a scale that a $4 \mathrm{~km}$ LAM is not able to resolve. The majority of the 66 raingauge locations show a close agreement in the timing of the rainfall, and the duration is quite well matched. The intensities are not similar, and it varies as to whether the model overestimates or underestimates the intensity.

This work has not taken into account any Areal Reduction Factors, which is a ratio of rainfall depth over an area to the rainfall depth of the same duration and return period at a representative point in the area (FEH, 2007), i.e. a correction factor for comparing point measurements to area averages. Keers and Wescott, 1977, suggest for the size of area chosen, and the durations observed, could be as large as 0.95 . This will be addressed in future work.

The locations which are not affected by orographic factors, e.g. in the Thames region where it is relatively flat, the observations and the model agree with the timing of the rainfall and the duration, with the raingauge intensity agreeing within an order of magnitude of the intensity predicted by the model. Differences occur when there are multiple rainfall events during the same day, which is not picked up in the model. This likely represents localised precipitation passing over the raingauge's location that cannot be accurately predicted at a $4 \mathrm{~km}$ resolution.

Large differences in timing, duration and intensity are seen for raingauges that are located in areas with large orographic forcing, i.e. the hills along the England/Wales border. This is likely due to the model having too coarse a resolution for local orography to cause an enhancement of the small scale system.

This highlights a problem when identifying possible future flooding events. Whilst the UK summer 2007 floods were widespread, one of the worst hit areas was the Gloucestershire region, which lies to the south of a set of hills on the England/Wales 
border. The location of the rainfall is extremely important to determine which area may get flooded.

\section{Discussion}

This paper has looked at two issues regarding potential future flooding events in the UK. The first issue is resolution. The results from the GCM show that with increases in resolution more extreme precipitation events are identified. The second issue is whether a warming climate will cause an increase in the number of extreme precipitation events. The GCM work showed that in a warmer climate there was a large decrease in the return rate of extreme precipitation events. This highlighted the risk of climate change on potential flooding events.

It is also clear that resolution is very important when forecasting intensities for localised extreme precipitation events. The LAM work showed that a $12 \mathrm{~km}$ forecast model was not able to pick up the extreme rainfall that was seen during the summer 2007 floods. The $4 \mathrm{~km}$ model was able to identify these events more accurately, when comparing these results to raingauges, however when there were multiple small scale systems in the same area, or when there was local orography, it struggled to get the timing or the intensities observed.

The next work in this study is to downscale events identified in the GCM to the LAM. The aim will be to get more information on a smaller scale on the effects of a warming climate on potential flooding events. This will also allow for the development of small scale storms within the larger scale extra-tropical storm that cannot occur with the GCM.

\section{References}

Bengtsson, L., Hodges, K. and Keenlyside, N. 2009. Will extra-tropical storms intensify in a warmer climate? J. Clim., 22, 2276 - 2301.

Easterling, D.R. et al. 2000. Climate Extremes: Observations, Modeling, and Impacts. Science. 289, 2068 - 2074.

Held, I.M. and Soden, B.J. 2006. Robust Responses of the Hydrological Cycle to Global Warming. J. Clim., 19, 5686 - 5699.

Hodges, K.I. 1995. Feature tracking on the unit sphere. Mon. Wea. Rev., 123, 3478 -3465 .

Hoskins, B. and Hodges, K. 2002. New perspectives on the northern hemisphere winter storm tracks. J. Atmos. Sci., 59, $1041-1061$.

Jones, P.D. and Reid, P.A. 2001. Assessing Future Changes in Extreme Precipitation over Britain using Regional Climate Model Integrations. Int. J. Climatol., 21, $1337-1356$. 
Keers, J.F. and Wescott, P. 1977. A computer-based model for design rainfall in the United Kingdom. Met Office Scientific Paper No. 36.

Kjeldsen, T.R. 2007. Flood Estimation Handbook Supplementary Report No. 1: The revitalised FSR/FEH rainfall-runoff method. Centre for Ecology and Hydrology. Tech. Report.

Murphy, J.M. and Mitchell, J.F.B. 1995. Transient Response of the Hadley Centre Coupled Ocean-Atmosphere Model to Increasing Carbon Dioxide. Part II: Spatial and Temporal Structure of Response. J. Clim., 8, 57 - 80.

Osborn, T.J., et al. 2000. Observed Trends in the Daily Intensity of United Kingdom Precipitation. Int. J. Climatol., 20, 6347 - 6364.

Roeckner, E., et al. 2003. The atmospheric general circulation model ECHAM5. Part I: Model description. Max Planck Institute for Meteorology. Tech. Report No. 349 ed.

Wilby, R.L., et al. 2008. Climate change and fluvial flood risk in the UK: more of the same? Hydrological Processes, 22, 2511-2523. 